\section{Perception of height as a linear function of attitude similarity*}

\author{
PAUL, R. BLEDA† \\ 1428 King Ave., Apt. 25, Columbus, Ohio 43212
}

The similarity of attitudes between two individuals had been proposed to function as an unconditioned stimulus (UCS). Perception of various stimuli (including people) has been found to be affected by associated conditions of reinforcement or value factors. Ss $(N=60)$ who had received different proportions of agreement from the same stimulus figure were asked to estimate that figure's height. Estimations of that figure's height tended to increase as attitudinal agreement was increased $(p<.02)$. In addition, both attraction and perceived height were found to be positively related linear functions of attitude similarity. These findings appear to lend further empirical support to the reinforcement model of attraction.

A number of investigations have demonstrated the differential effects of attitudinal agreement and disagreement on behavior. Several experiments (Golightly \& Byrne, 1964; Byrne, Young, \& Griffitt, 1966; Byrne, Griffitt, \& Clore, 1968) have shown that response probabilities within a discrimination learning situation are affected by different attitudinal outcomes. Other research (Smith \& Jeffery, 1970) has indicated that individuals of high and low social-evaluative anxiety respond differentially to similar and dissimilar attitude statements. Particular types of physiological responses (GSR arousal, pupillary dilation and constriction) were also found to be differentially affected by conditions of agreement and disagreement (Gormly, 1971; Hess, 1965).

A reinforcement model has been used to interpret these findings (Byrne \& Clore, 1970). A basic premise of this model is that attitude similarity between individuals functions as an unconditioned stimulus (UCS). The affective reaction (UCR) evoked in one individual by agreement or disagreement is assumed to become associated with the other individual. By this process of conditioning, a previously unknown and presumably neutral person (CS) will come to elicit an implicit conditioned response (CR), which may be manifested in the form of a personal evaluation. One such evaluative response, attraction, has been found to be a positive linear function of attitude similarity (Byrne \& Nelson, 1965). Broader support for the reinforcement model could be derived from its ability to predict

*The author wishes to thank Sharon Bleda and Don Moeser for their assistance and Donn Byrne and Joel Saegert for their comments and suggestions.

+ Requests for reprints should be addressed to Paul Bleda, 1428 King Ave., Apt. 25, Columbus, Ohio 43212 . other related behavioral phenomena.

Past research has demonstrated that perceptual accentuation of a stimulus object can occur when associated with conditions of positive reinforcement. Lambert et al (1949) found that the apparent size of an originally neutral stimulus object was judged greater when associated with natural reward than either before conditions of reinforcement or after extinction. In addition, a person used as a stimulus figure has been found to be amenable to perceptual distortion due to associated value factors. In a recent investigation, Ss' estimations of a stimulus figure's height tended to increase as his ascribed academic status was increased (Wilson, 1968).

On the basis of the reinforcement model and findings concerning the effects of reinforcement on perception, the following hypothesis was derived: the estimated height of a stimulus figure is a positive linear function of the proportion of similar attitudes associated with that figure. Since the S's actual height was considered to be a possible source of extraneous variability in testing the hypothesis, this factor was systematically varied. \section{METHOD}

In an initial session, a 20-item attitude questionnaire was administered to students enrolled in an introductory sociology course at Ohio State University. Included on the questionnaire were topics such as the women's liberation movement, dancing, and belief in God. $S$ responses were made on a 6-point scale. Seventy-two female volunteers were divided equally into six matched groups consisting of four tall (ht $\geqslant$ 67 in.), four medium (64 in. $<$ ht $<$ 67 in.), and four short (ht $\leqslant 64$ in.) Ss. ${ }^{1}$ Each group was then assigned randomly to one of five experimental and one control condition. The proportions of attitude agreement in the experimental conditions were .10 ,
$.30, .50, .70$, and .90 . The control group received neither agreement nor disagreement.

In a second experimental session, each $\mathrm{S}$ was conducted individually into the experimental room by a female assistant. The $\mathbf{S}$ was then positioned a standard distance away from and facing a large constructed frame covered with a semitransparent cloth screen. $^{2}$ The $\mathrm{E}$, who served as the stimulus figure under all conditions, was standing on the opposite side of the screen, posing as another $\mathrm{S}$. A double-blind procedure was used to control for possible $\mathrm{E}$ influence. ${ }^{3}$ The assistant explained the purpose of the experiment as a test of the Ss' ability to make judgments about another person based on only a limited amount of information. The information was provided in the form of the other person's questionnaire. Actually, the real S received a "bogus" questionnaire completed to agree with a certain proportion of her attitudes. After inspecting these questionnaires, each " $S$ " was asked to complete a modified version of the Interpersonal Judgment Scale (Byrne, 1961). Included on this scale were two items (likability and desirability as a work partner) that have been previously combined to yield a standard index of attraction (Byrne, 1971, p. 52). A question was also included on the scale which required an estimation of the other individual's height to the nearest half inch.

\section{RESULTS}

Means and standard deviations of the estimated height of the stimulus figure for groups receiving different proportions of similar attitudes are given in Table 1. A comparison of the mean height ( 71.50 in.) estimated by Ss receiving $90 \%$ agreement and the mean estimated height (69.58 in.) of those receiving $30 \%$ agreement reveals a difference of almast 2 in. The control group which received neither agreement nor disagreement judged the stimulus figure to be $69.67 \mathrm{in}$. Mean estimations of the stimulus figure's height for all groups were greater than his actual height of 68.75 in. This consistent perceptual distortion may have been due to this individual's particular body build and weight $(186 \mathrm{lb})$, which exceeded the average weight (166 lb) for men of his height (U.S. Dept. H.E.W., 1966, p. 11)

Orthogonal polynomials (Edwards, 1960 , p. 150) were applied to the group totals of estimated height to test for the predicted linear relationship between attitude similarity and perceived height. The results of this planned comparison were found to be statistically significant $(\mathrm{F}=7.10, \mathrm{df}=$ $1 / 45, \mathrm{p}<.02)$. Neither the actual 
Table 1

Means and Standard Deviations of the Estimated Height of a Stimulus Figure According to Proportion of Similar Attitudes

\begin{tabular}{ccc}
$\begin{array}{c}\text { Proportion of } \\
\text { Similar Attitudes } \\
\text { Associated With }\end{array}$ & $\begin{array}{c}\text { Mean Estimated } \\
\text { Height (Inches) } \\
\text { of Stimulus } \\
\text { Ftimulus Figure* }\end{array}$ & $\begin{array}{c}\text { SDs (Inches) of } \\
\text { Height Estimations } \\
\text { of Stimulus } \\
\text { Figure }\end{array}$ \\
\hline .10 & 69.75 & 2.01 \\
.30 & 69.58 & 1.99 \\
.50 & 70.42 & 2.08 \\
.70 & 70.88 & 1.70 \\
.90 & 71.50 & 1.81 \\
\hline
\end{tabular}

*Each group was based on $N=12$.

height of the $S$ nor the interaction of this variable with attitude similarity was found to have significant effects on estimated height $(F=1.66, \mathrm{df}=$ $2 / 45, \mathrm{p}>.05$, and $\mathrm{F}=1.11, \mathrm{~d} \mathrm{f}=8 / 45$, $\mathrm{p}>.05$, respectively).

An analysis of variance indicated that the effects of attitude similarity on the standard index of attraction was statistically significant $(F=5.16$, $\mathrm{df}=4 / 55, \mathrm{p}<.005)$. Orthogonal polynomials were then applied to the group totals of the standard index of attraction in order to ascertain the form of the relationship. Only the variation due to the linear trend in the data was found to be statistically significant $(\mathrm{F}=16.61, \mathrm{df}=1 / 55$, $\mathrm{p}<.001$ ).

To test for a possible relationship between attraction and perceived height, a Pearson product-moment correlation was computed, using the Ss' scores on these two variables. The results of this correlational analysis indicated a statistically significant positive relationship between attraction and perceived height $(r=$ $.34, \mathrm{df}=58, \mathrm{p}<.01)$.

\section{DISCUSSION}

The proportion of similar attitudes associated with another person was found to affect the perception of that person's size. More specifically, perceived height was found to be a positive linear function of attitude similarity. This finding seems to yield further empirical support for the reinforcement interpretation of the effects of attitudinal agreement and disagreement on behavior.

In accordance with the empirically derived law of attraction, the present investigation also found that attraction was a positive linear function of attitude similarity. Furthermore, the evaluative responses of attraction and perceived height were found to be positively correlated. Recent findings relevant to this attraction-perceived height relationship have indicated that actual height is positively associated with success in business and politics (Wall Street Journal, 1969; Feldman, 1971). These findings have strongly suggested that there may be greater attraction in the American society toward taller individuals than for shorter ones. The present findings seem to also suggest that the greater attraction one has toward another individual, the taller he will perceive him to be.

\section{REFERENCES}

BYRNE, D. Interpersonal attraction and attitude similarity. Journal of Abnormal \& Social Psychology 1961,62, 713-715.

BYRNE, D. The attraction paradigm. New York: Academic Press, 1971.

BYRNE, D., \& CLORE, G. L. A reinforcement model of evaluative responses. Personality: An International Journal, 1970, 1, 103-128.

BYRNE, D., GRIFFITT, W., \& CLORE. G. L. Attitudinal reinforcement effects as a f u n c t i o $n$ of $s$ i $m$ u l u s homogeneity-heterogeneity. Journal of Verbal Learning \& Verbal Behavior, $1968,7,962-964$
BYRNE, D., \& NELSON, D. Attraction as a linear function of proportion of positive reinforcements. Journal of Personality \& Social Psychology, 1965, 1, 659-663.

BYRNE. D., YOUNG, R. K.. \& GRIFFITT W. The reinforcement properties of attitude statements. Journal of Experimental Research in Personality. 1966, 1, 266-276.

EDWARDS, A. L. Experimental design in psychological research. New York: Holt, Rinehart \& Winston, 1960.

FELDMAN, S. D. The presentation of shortness in everyday life-height and heightism in American society: Toward a sociology of stature. Paper presented at the American Sociological Association meeting, Denver, 1971 .

GOLIGHTLY, C., \& BYRNE, D. Attitude statements as positive and negative reinforcements. Science, 1964, 146 , $798-799$.

GORMLY. J. B. Sociobehavioral and physiological responses to interpersonal disagreement. Journal of Experimental Research in Personality, 1971, 5 . 216-222.

HESS, E. H. Attitude and pupil size. Scientific American, $1965,212,400-408$

LAMBERT, W. W., SOLOMON, R. L., \& WATSON, P. D. Reinforcement and extinction as factors in size estimation. Journal of Experimental Psychology, 1949, 39, 637-641.

SMITH, R. E., \& JEFFERY, R. W Social-evaluative anxiety and the reinforcement properties of agreeing and disagreeing attitude statements. Journal of Experimental Research in Personality, $1970,4,276-280$

U.S. DEPT. OF HEALTH EDUCATION \& WELFARE. Weight by height and age of adults: United States-1960-1962. Vital and health statistics. Public Health Service Publication No. 1000, Series 11 , No. 14. Washington, D.C: U.S. Government Printing Office, May 1966. P. 11.

WALL STREET JOURNAL. Labor letter. November 25, 1969. P. 1.

WILSON, P. R. Perceptual distortion of height as a function of ascribed academic status. Journal of Social Psychology. $1968,74,97-102$.

\section{NOTES}

1. The S's actual height was obtained from a personal information card completed previously.

2. The semitransparent screen provided a relatively ambiguous stimulus arrangement which would be conducive to perceptual error.

3. The $S$ 's identity was not revealed to the $\mathrm{E}$ while posing as the stimulus figure. In addition, the assistant did not know which treatment condition each $S$ received. 